\title{
Spinal cord lesions in heat stroke
}

\author{
GABRIEL DELGADO, TERESA TUÑÓN, JAIME GÁllEgo, JOSÉ A VILLANUEVA \\ From the Servicios de Neurologia y Anatomia Patológica, Hospital de Navarra, Pamplona, Spain
}

SUMMARY A clinical and pathological report of a patient who died 15 days after suffering a classic heat stroke is presented. The clinical picture was of a flaccid quadriplegia with anhidrosis and sphincter disturbance. The most severe pathological lesions were to be seen in the anterior and intermedio-lateral horns of the spinal cord. Hyperthermia was the only physiopathological mechanism demonstrated in the patient. It is suggested that the motor neurons and vegetative neurons of the spinal cord are specially sensitive to hyperthermia.

There is a considerable literature, as listed in recent reviews, on the epidemiology, pathogenesis, physiopathology and clinical features of heat stroke. ${ }^{1-4}$ There are few neuropathological studies, in spite of the fact that there are always characteristic signs and symptoms of neurological involvement. The basic neuropathology reference work is still that by Malamud et al in 1946, who studied 125 fatal cases of heat stroke induced by physical exercise ${ }^{5}$ and described characteristic lesions in the cerebrum, cerebellum and skeletal muscles. This paper presents a clinical and pathological study of a case of classic heat stroke, with no damage to the cerebrum but with severe neuronal lesions in the spinal cord.

\section{Case report}

A 66-year-old man was referred to the Hospital of Navarra; for the previous 3 hours he had remittent rightsided somatomotor partial seizures with secondary generalisation. The patient, who suffered from manic depressive psychosis, was a long term in-patient of a psychiatric hospital which had no air-conditioning. He had been receiving continuous medication with amitryptiline ( $30 \mathrm{mg} /$ day), imipramine ( $75 \mathrm{mg} /$ day) and pherphenazine ( $6 \mathrm{mg} /$ day). For the previous few days, the region had a heat wave with maximum temperatures of $38^{\circ} \mathrm{C}$. The fits did not reappear after the administration of iv clonazepam $2 \mathrm{mg}$. The patient, who was very obese, had a rectal temperature of $42.5^{\circ} \mathrm{C}$ and his skin was hot and dry. Blood pressure was $120 / 70 \mathrm{~mm} \mathrm{Hg}$ and pulse $120 / \mathrm{min}$ with normal sinus rhythm. There were no other abnormalities on physical

Address for reprint requests: Dr Gabriel Delgado, Servicio de Neurologia, Hospital de Navarra, Pamplona, Spain

Received 4 December 1984 and in revised form 15 March 1985. Accepted 23 March 1985. examination. Neurological examination was normal except for a moderate drowsiness and mental confusion. Routine biological tests, including electrolytes, $\mathrm{pH}$ and clotting were normal except for a leucocytosis of $10.000 \mathrm{cells} / \mathrm{mm}^{3}$. CT scan and CSF were normal. The EEG recording was diffusely slowed $(5 \mathrm{~Hz})$. The rectal temperature was reduced to $38^{\circ} \mathrm{C}$ by physical means of cooling over the following 10 hours. Twelve hours after admission, the patient developed an acute respiratory insufficiency owing to weakness of the respiratory muscles and required endotracheal intubation and mechanical ventilation. At the same time he was found to be quadriplegic, with muscular hypotonia, absence of muscle stretch and skin reflexes, retention of urine and faecal incontinence. The cranial nerves, sensation and the level of consciousness were preserved. This neurological situation continued without change for 14 days, after which the patient suddenly died. During all this time, no sweating was seen, continuous physical cooling methods being required to maintain a normal body temperature. During the first 72 hours of the course of this illness, there was a rise in the skeletal isoenzyme of serum creatine kinase to $9.950 \mathrm{U} / \mathrm{ml}$, which gradually became normal over the next few days. At no time was there severe hypoxia or circulatory collapse.

\section{Pathological findings}

The abnormal pathological findings were confined to skeletal muscle and the nervous system. The rest of study revealed only a moderately fatty liver. The cerebral hemispheres and the brain stem were macroscopically and histologically normal. In the cerebellum, there was almost total loss of Purkinje cells, without proliferation of Bergmann glia, and necrosis of the granular layer (fig 1, A). The dentate nucleus also showed neuronal loss without gliosis. With the myelin stains, a diffuse pallor of the cerebellar white matter could be seen, which was most marked in the hilus of the dentate nucleus (fig 1, B). Throughout the spinal cord there were marked neuronal abnormalities in the anterior and intermedio-lateral horns, with chromatolysis 

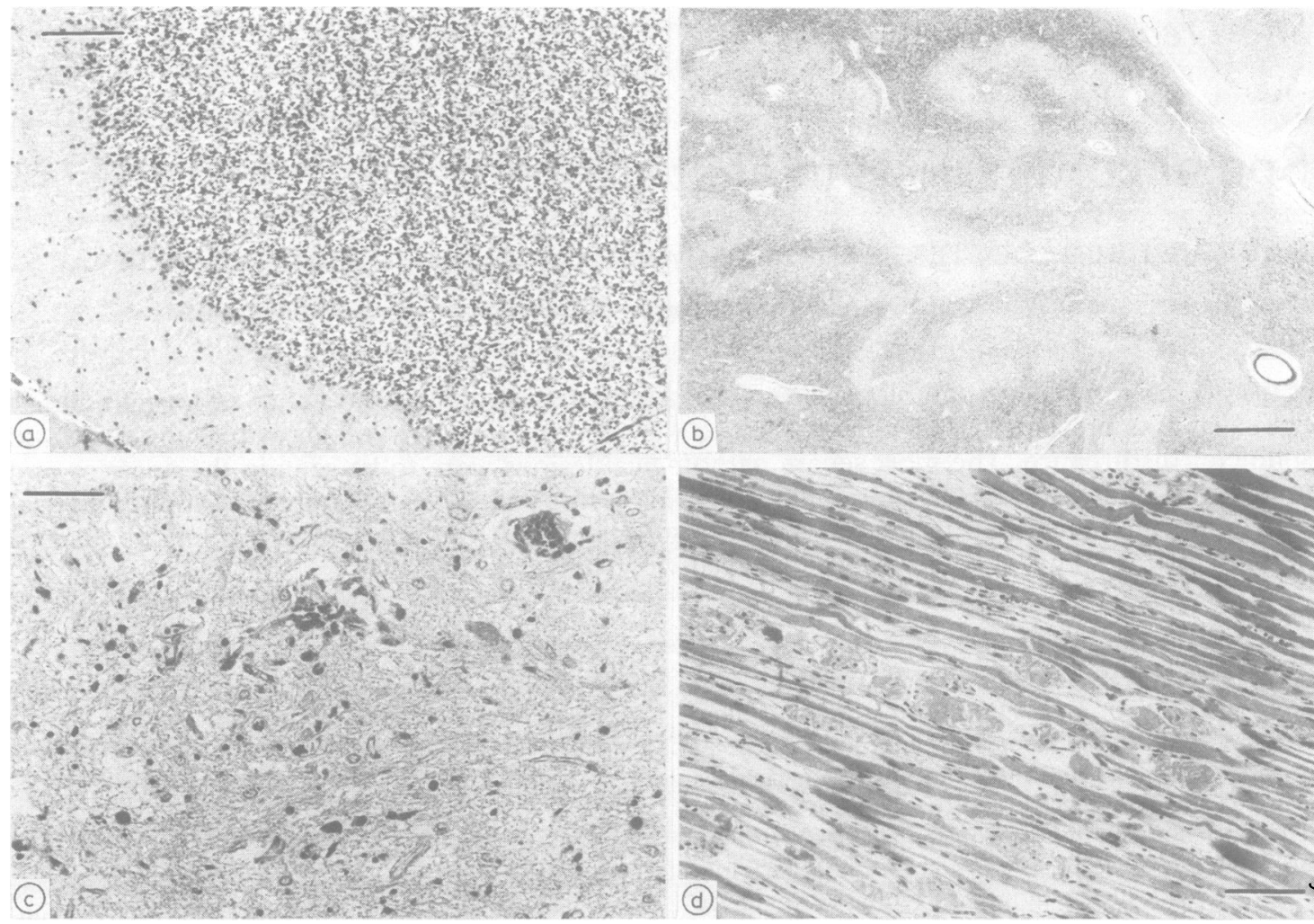

Fig 1 (A) Cerebellar cortex shows marked loss of Purkinje cells without proliferation of Bergmann glia. Necrosis of the cells of the granular layer can be seen. Haematoxylin \& eosin; bar $=25 \mu \mathrm{m}$. (B) Cerebellar cortex and dentate nucleus. Note myelin pallor in the hilus of the dentate nucleus. Spielmeyer; bar $=2 \mathrm{~mm}$. (C) Anterior horn of the lumbar spinal cord. There is a total loss of motor neurons, abundant macrophages loaded with lipofuscin and fibrillar and hypertrophic gliosis. $P A S ; b a r=25 \mu m .(D)$ Longitudinal section of quadriceps femoris. Numerous muscle fibres are necrotic, others show regeneration. Haematoxylin \& eosin; bar $=25 \mu \mathrm{m}$.

and neuronophagia (fig $1, \mathrm{C}$ ). In the anterior roots numerous axons were seen to be interrupted, with abundant macrophages phagocytosing myelin. There were no lesions in the posterior horns and roots or in the spinal cord tracts. The sympathetic ganglia and the sural nerve were normal. Skeletal muscle showed severe rhabdomyolysis with regeneration (fig $1, D)$. Using histochemical techniques, the presence of angular fibres with inversion of the oxidative enzymatic pattern and numerous target fibres could be seen.

\section{Discussion}

There were many risk factors for heat stroke in this case: obesity, advanced age, institutionalisation, lack of air-conditioning and a heat wave at the beginning of the summer. ${ }^{6}$ The latter meteorological factor is associated with high morbidity and mortality due to heat stroke. ${ }^{7}$ One cannot exclude the possibility that the psychotropic drugs he was taking might have been contributors, because of their anticholinergic, alpha-adrenergic blocking and hypothalamic-suppressing actions. ${ }^{89}$

Heat stroke runs its course with serious electrolyte disturbances, circulatory collapse and disseminated intravascular coagulation. ${ }^{124510}$ This combination of multiple physiopathological factors makes it unlikely that in most cases hyperthermia per se is responsible for production of nervous system lesions. This present case is a rare instance of heat stroke with no other demonstrable physiopathological mechanism than hyperthermia. Rhabdomyolysis, unusual in classical heat stroke, but a constant finding in that induced by exercise, might in this case have been caused by convulsive seizures.' Apart from this, the only pathological lesions were found in the nervous system, in the cerebellum and spinal cord. Generally it is assumed, in accord with Malamud et al ${ }^{5}$ that the neuronal lesions in the cere- 
bral cortex, basal ganglia and cerebellum are a direct effect of the hyperthermia. In the present case, the cerebellum had lesions similar to those described by Malamud et al, ${ }^{5}$ consistent with the fact that a cerebellar syndrome is the most frequent permanent neurological sequela of the heat stroke. ${ }^{9}$ The absence of lesions in the cerebrum in this case does not support the hypothesis of a greater sensitivity of cortical neurons to hyperthermia.

The most prominent clinical feature in this case was the acute onset of the quadriplegia with anhidrosis, bladder paralysis and faecal incontinence, without sensory disturbances. Eight cases in the series of Malamud et al are reported as having flaccidity ${ }^{5}$ but spinal cord or peripheral nerve lesions were not described. Mehta and Baker's case of classic heat stroke had flaccid quadriparesis, anhidrosis and sphincter disturbances which persisted 11 years after heat stroke. ${ }^{11}$ Their review of the literature includes seven other cases with quadriparesis and lower motor neuron signs. It was suggested that the underlying neuropathological factor in their patient was a thermal lesion in the peripheral nervous system, basing their hypothesis on the slowing of motor conduction velocity. In the present case, the clinical picture is completely accounted for by the spinal cord lesions. The flaccid quadriplegia can be correlated with the severe damage to the anterior horn cells. The undamaged sural nerve excludes a direct thermal lesion of the peripheral nerves. Unfortunately the histology of the sweat glands was not studied. Hence, heat damage to them cannot be excluded, a finding which is reported in some cases. ${ }^{1}$ Nevertheless, the patient's persistent anhidrosis can be explained by the damage to the preganglionic sympathetic neuron in the intermedio-lateral horn alone. The histologically undamaged state of the hypothalamus, sympathetic ganglia and the sural nerve do not suggest any alternative hypothesis. These findings indicate that anhidrosis, a frequent but not constant sign in heat stroke, may be a consequence rather than a physiopathological mechanism causing hyperthermia. The sphincter disturbances can also be correlated with the lesion of the intermedio-lateral horn, where the centres for control of the bladder and rectal sphincters probably are located. ${ }^{12}$
The neuropathological findings in this unusual case suggest that the spinal cord, in addition to the cerebellum, is a region of the nervous system particularly sensitive to hyperthermia.

We thank Dr Obeso for helpful suggestions.

\section{References}

${ }^{1}$ Knochel JP. Environmental heat illness. An eclectic review. Arch Intern Med 1974;133:841-64.

${ }^{2}$ Goetz CG, Klawans HL. Hyperthermic states: Heat stroke and malignant hyperthermia. In: Vinken PJ, Bruyn GW eds: Handbook of Clinical Neurology, Vol 38. Amsterdam, Elsevier/North-Holland Biomedical Press, 1979:543-61.

${ }^{3}$ Hart GR, Anderson RJ, Crumpler CP, Shulkin A, Reed G, Knochel JP. Epidemic classical heat stroke: Clinical characteristics and course of 28 patients. Medicine (Baltimore) 1982;61:189-97.

${ }^{4}$ Anderson RJ, Reed G, Knochel J. Heatstroke. In: Stollerman GH et: Advances in Interna Medicine, Vol 28. Year Book Publishers, Inc, 1983:115-40.

${ }^{5}$ Malamud N, Haymaker W, Custer RP. Heat stroke. A clinico-pathologic study of 125 fatal cases. Milit Surg 1946;99:397-449.

- Kilbourne EM, Choi K, Jones TS, Thacker SB. Risk factors for heat stroke. A case-control study. JAMA 1982;247:3332-6.

7 Jones TS, Liang AP, Kilbourne EM, et al. Morbidity and mortality associated with the July 1980 heat wave in St. Louis and Kansas City, Mc. JAMA 1982;247: 3327-31.

${ }^{8}$ Mann SC, Boger WP. Psychotropic drugs, summer heat and humidity, and hyperpyrexia: a danger restated. Am J Psychiatry 1978;135:1097-100.

${ }^{9}$ Lefkowitz D, Ford CS, Rich C, Biller J, McHenry LC Jr. Cerebellar syndrome following neuroleptic induced heat stroke. J Neurol Neurosurg Psychiatry 1983; 46: $183-5$.

${ }^{10}$ Chao TC, Sinnah R, Pakiam JE. Acute heat stroke deaths. Pathology 1981;13:145-56.

"Mehta AC, Baker RN. Persistent neurological deficits in heat stroke. Neurology (Minneap) 1970;20:336-40.

${ }^{12}$ Mannen T, Iwata M, Toyokura Y, Nagashima K. Preservation of a certain motoneurone group of the sacral cord in amyotrophic lateral sclerosis: Its clinical significance. J Neurol Neurosurg Psychiatry 1977;40:464-9. 